\title{
Viabilidade da técnica de transposição uretral pré-púbica mediante secção peniana em cadáveres de cães
}

\author{
[Viability of the prepubic urethral transposition technique by penile section in dog cadavers] \\ P. Vives ${ }^{1}$, F.A. Braga ${ }^{2}$, J. Rappeti ${ }^{2}$, V. Milech ${ }^{1}$, B. Maroneze ${ }^{2}$, C. Lima ${ }^{2}$, \\ S. Rausch ${ }^{3}$, E. Moraes ${ }^{3}$, R. Baumhardt ${ }^{4}$, A. Mazzanti ${ }^{5 *}$ \\ ${ }^{1}$ Aluno de pós-graduação - Universidade Federal de Santa Maria - Santa Maria, RS \\ ${ }^{2}$ Universidade Federal de Pelotas - Pelotas, RS \\ ${ }^{3}$ Médico veterinário autônomo \\ ${ }^{4}$ Universidade Regional do Noroeste do Estado do Rio Grande do Sul - Ijuí, RS \\ ${ }^{5}$ Universidade Federal de Santa Maria - Santa Maria, RS
}

\begin{abstract}
RESUMO
Descreve-se a viabilidade da técnica cirúrgica de transposição uretral pré-púbica em cadáveres de cães machos, adultos, advindos de um hospital veterinário, a fim de se avaliar a manutenção da luz uretral a partir de um desvio uretral pré-púbico, descrevendo-se detalhadamente a abordagem e as estruturas anatômicas envolvidas. A técnica consistiu inicialmente da orquiectomia, seguida de celiotomia retroumbilical, tração vesical cranial, secção transversa da uretra membranosa a $1 \mathrm{~cm}$ caudal à próstata, espatulação e reparo da borda livre. A seguir, divulsão e secção do pênis $1,5 \mathrm{~cm}$ caudal ao osso peniano, espatulação da borda uretral peniana e transposição desta em direção à cavidade abdominal, fazendo-se anastomose por meio de sutura interrompida simples à uretra membranosa. Foi mensurado o comprimento uretral desde o meato externo até o início da uretra prostática em dois momentos: pré e pós-transposição. Ao final, avaliou-se, por meio de uretrografia retrógrada de contraste positivo, o diâmetro e o selamento na anastomose uretral e o fluxo do contraste até a bexiga. A transposição uretral pré-púbica é uma técnica cirúrgica exequível, anatomicamente compatível com a espécie canina e capaz de manter o diâmetro uretral e o fluxo do contraste de forma satisfatória, com manutenção estética externa idêntica a um cão macho orquiectomizado.
\end{abstract}

Palavras-chave: obstrução uretral, anastomose, desvio uretral, uretrografia, modelo biológico

\begin{abstract}
We describe the viability of the surgical technique of pre-pubic urethral transposition in cadavers of adult male dogs, coming from a veterinary hospital to evaluate the maintenance of urethral light from a prepubic urethral deviation, describing in detail the approach and anatomical structures involved. The technique consisted initially of orchiectomy, followed by retroumbilical celiotomy, cranial vesical traction, transverse section of the membranous urethra at $1 \mathrm{~cm}$ caudal to prostate, spatulation and free edge repair. Next, the penis divulsion and section $1.5 \mathrm{~cm}$ caudal to the penile bone, spreading the penile urethral border and transposing it towards the abdominal cavity, making an anastomosis of simple interrupted suture to the membranous urethra. The dogs had the urethral length measured from the external meatus to the beginning of the prostatic urethra at two moments: pre-transposition and post-transposition. Postoperative retrograde urethrography was used to evaluate the diameter and sealing of the urethral anastomosis and contrast flow to the bladder. In conclusion, the prepubic urethral transposition is a feasible surgical technique, anatomically compatible with the canine species and able to maintain the urethral diameter and contrast flow satisfactorily, with an external esthetic maintenance identical to an orchiectomized male dog.
\end{abstract}

Keywords: urethral obstruction, anastomosis, urethral deviation, urethrography, biological model

\section{INTRODUÇÃO}

A estenose uretral é uma das principais causas de disfunções miccionais (Ghozzi et al., 2010) e, em cães, frequentemente está relacionada a traumas no trato urinário (Kemper et al., 2011), associada às fraturas pélvicas (Brinker et al., 2009).

Recebido em 21 de fevereiro de 2017

Aceito em 9 de junho de 2017

*Autor para correspondência (corresponding autor)

E-mail: alexamazza@yahoo.com.br 
Os sinais de estenose uretral incluem aqueles relacionados à estase urinária e o diagnóstico deve ser realizado por meio de uretrocistografia retrógrada com contraste positivo (URCP) (Raney et al., 1977; Bjorling, 2003; Kealy e Mcallister, 2010).

As lesões da uretra intrapélvica são pouco frequentes em razão da proteção anatômica; o reparo é considerado desafiador, uma vez que o acesso é mais complexo e com frequência resulta em estenose. Além disso, deformidades luminais com perdas teciduais extensas requerem várias intervenções cirúrgicas (Ghozzi et al., 2010; Ximenes e Souza Neto, 2010; Kemper et al., 2011).

Diversas técnicas cirúrgicas estão recomendadas no reparo de estenoses da uretra anterior em humanos. A uretroplastia com anastomose término-terminal apresenta melhores resultados, mas está indicada nas contrições curtas. As estenoses moderadas com ressecção de 2 a $4 \mathrm{~cm}$ exigem manobras de aproximação fazendo-se um discreto desvio uretral, no entanto as lesões extensas necessitam de enxertos ou de retalhos substitutos para restituir o fluxo urinário (Ximenes e Souza Neto, 2010; Barbagli et al., 2012; Regueiro et al., 2012).

Na medicina veterinária, poucas alternativas são encontradas na literatura, e nas estenoses uretrais intrapélvicas com mais de $2 \mathrm{~cm}$, o tratamento usual é a uretrostomia pré-púbica, técnica relacionada a diversas complicações (Smeak, 2000). Nesse contexto, é notória a necessidade de estudos acerca do reparo uretral em cães.

A transposição uretral pré-púbica mediante secção peniana foi proposta por Vives et al. (2017) para restaurar o fluxo urinário de um cão acometido de estenose uretral extensa como alternativa à uretrostomia pré-púbica. Esses autores relataram manutenção da luz uretral e ausência de sinais clínicos de constrição, entretanto trata-se de um relato de um caso, o que requer maiores estudos acerca dessa técnica prévia à recomendação na rotina clínicacirúrgica, visto que diversas dúvidas são pertinentes, como as estruturas anatômicas envolvidas e o restabelecimento do fluxo urinário.

Diante do exposto, objetiva-se avaliar a viabilidade cirúrgica da transposição em cadáveres caninos, descrever as estruturas anatômicas abordadas e analisar a manutenção da luz por meio de um desvio uretral.

\section{MATERIAL E MÉTODOS}

Foram utilizados 18 cadáveres frescos de cães machos, adultos, provenientes do Hospital de Clínicas Veterinária da Universidade Federal de Pelotas (HCV-UFPel), com óbito por causas naturais ou com indicação médica de eutanásia. Apresentavam idade entre dois e 13 anos, peso entre 5,5 e 11,6 quilos de massa corpórea, $11 \%$ eram castrados e $72 \%$ sem raça definida, conforme distribuição na Tab. 1.

Este experimento obedeceu aos critérios éticos sugeridos no Brasil pelo Concea (Colégio Nacional de Controle de Experimentação Animal), para uso de animais em experimentação, conforme parecer favorável do Ceea (Comitê de Ética em Experimentação Animal) da UFPel, registrado sob o número 23110.004612/2016-03.

Para empregar a técnica, cada animal foi posicionado em decúbito dorsal e submetido à tricotomia do abdome e da pelve. Uma sonda uretral calibre entre 6 e 8 French foi introduzida a partir da uretra peniana até a vesícula urinária. $\mathrm{Na}$ sequência, fez-se incisão cutânea retroumbilical com desvio paraprepucial à direita até a borda cranial do púbis, orquiectomia dos cães não castrados e celiotomia sobre a linha alba.

A vesícula urinária foi identificada e a sonda uretral foi posicionada até o início da uretra membranosa para mensuração do comprimento desde o meato uretral externo. A sonda foi marcada, removida e colocada sobre uma régua graduada em $\mathrm{cm}$ para obter-se o comprimento uretral inicial, excluindo-se a uretra prostática. 
Tabela 1. Distribuição das características dos cadáveres utilizados para a execução da técnica de transposição uretral pré-púbica (TUPP) quanto ao peso, à raça, à idade, ao estado reprodutivo e à causa do óbito

\begin{tabular}{|c|c|c|c|c|c|}
\hline Variáveis & Peso (kg) & $\begin{array}{l}\text { Idade } \\
\text { (Anos) }\end{array}$ & Raça & Causa do óbito & $\begin{array}{l}\text { Estado } \\
\text { reprodutivo }\end{array}$ \\
\hline Cão 1 & 8,2 & 5 & Srd & Trauma & Não castrado \\
\hline Cão 2 & 6,8 & 11 & Srd & Insuficiência renal & Não castrado \\
\hline Cão 3 & 7,2 & 3 & Srd & Trauma & Não castrado \\
\hline Cão 4 & 6,5 & 4 & Poodle & Intoxicação & Não castrado \\
\hline Cão 5 & 11 & 8 & Srd & Insuficiência renal & Não castrado \\
\hline Cão 6 & 7,4 & 9 & Srd & Trauma & Não castrado \\
\hline Cão 7 & 9,5 & 5 & Srd & Trauma & Não castrado \\
\hline Cão 8 & 6,6 & 8 & Yorkshire & Trauma & Não castrado \\
\hline Cão 9 & 9,6 & 2 & Srd & Trauma & Não castrado \\
\hline Cão 10 & 9,1 & 3 & Pug & Enterite & Castrado \\
\hline Cão 11 & 8,7 & 13 & Srd & Trauma & Não castrado \\
\hline Cão 12 & 6 & 4 & Srd & Trauma & Não castrado \\
\hline Cão 13 & 11,6 & 12 & Srd & Insuficiência renal & Não castrado \\
\hline Cão 14 & 7,2 & 5 & Srd & Pancreatite & Não castrado \\
\hline Cão 15 & 6 & 2 & Poodle & Intoxicação & Não castrado \\
\hline Cão 16 & 8,8 & 5 & Srd & Sem diagnóstico & Castrado \\
\hline Cão 17 & 5,5 & 13 & Teckel & Oncológico terminal & Não castrado \\
\hline Cão 18 & 9 & 11 & Srd & Insuficiência renal & Não castrado \\
\hline
\end{tabular}

Fonte: Arquivo pessoal, Srd - Sem raça definida.

A vesícula urinária foi tracionada cranialmente até que a próstata e a porção inicial da uretra membranosa fossem evidenciadas (Fig. 1A), isolando-a por meio de dissecção romba, preservando-se os ramos uretrais dorsolaterais distais da artéria prostática que emergem da artéria pudenda interna, os ramos distais dos nervos pélvicos e os ramos uretrais do nervo pudendo. Procedeu-se à secção transversal da uretra $1 \mathrm{~cm}$ distal à próstata (Fig. 1B) e à espatulação da extremidade livre, por meio de uma incisão linear ventral de $0,5 \mathrm{~cm}$ perpendicular à secção (Fig. 1C). A sonda uretral foi reposicionada a partir da uretra peniana para o interior da vesícula urinária (Fig. 1D).

A seguir, o pênis foi delicadamente divulsionado na região pré-escrotal, $2 \mathrm{~cm}$ caudal ao osso peniano até alcançar a fáscia e a túnica albugínea. Estas, já liberadas nas faces ventral, lateral e dorsal, foram seccionadas transversalmente $1,5 \mathrm{~cm}$ distal ao osso peniano, entretanto preservando-se as artérias e veias dorsais do pênis e os vasos prepuciais (Fig. 1E). O segmento uretral esponjoso também foi espatulado por meio de uma incisão linear ventral de $1 \mathrm{~cm}$ perpendicular à secção, conferindo triangulação da extremidade (Fig. 1F), maior amplitude no diâmetro e compatibilidade entre as bordas.

A anastomose ocorreu cranial ao púbis, sobre o cateter, a partir de uma sutura interrompida simples, utilizando-se fio de náilon monofilamentar 4-0, cujo primeiro ponto foi posicionado às 12 horas (Fig. 1G) e, na sequência, um ponto à direita, outro à esquerda, sucessivamente, até que o último fosse posicionado em seis horas. Manteve-se o intervalo de $1 \mathrm{~mm}$ entre cada ponto até completa aposição das bordas (Fig. 1H). A seguir, a vesícula urinária foi preenchida com solução salina $0,9 \%$ para conferir o selamento e certificar-se de que não haveria extravasamento na sutura.

O comprimento uretral pós-cirúrgico foi aferido por meio da sonda previamente posicionada, marcando-se a distância entre o óstio uretral da glande e a borda caudal da próstata colocando-se essa sonda novamente sobre a régua. 

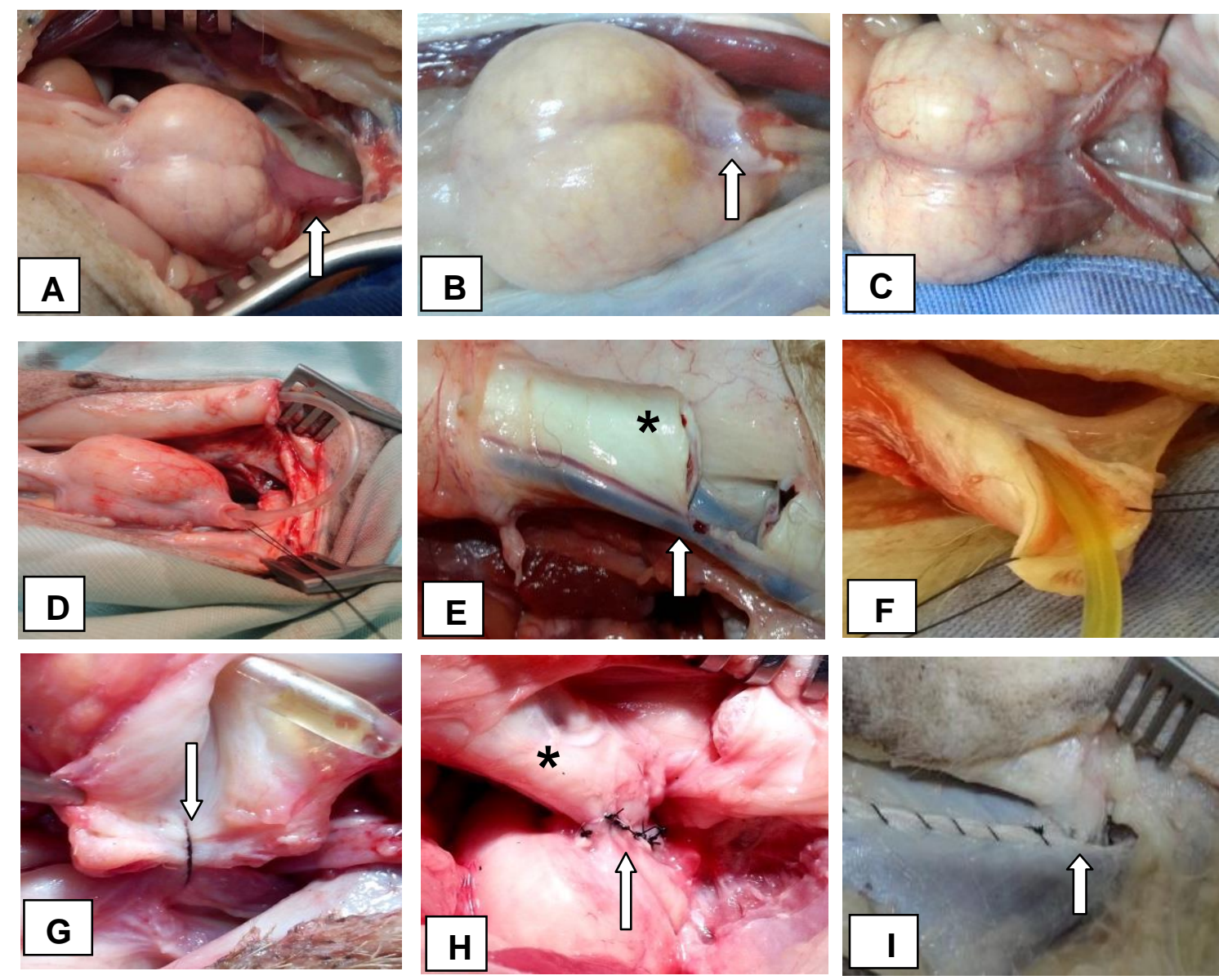

Figura 1. Imagens da técnica cirúrgica de transposição uretral pré-púbica mediante secção peniana em cadáveres de cães machos. (A) Exposição da uretra membranosa (seta) por tração cranial da vesícula urinária. (B) Secção transversal da uretra membranosa a $1 \mathrm{~cm}$ da próstata (seta). (C) Incisão longitudinal ventral de $0,5 \mathrm{~cm}$ da uretra membranosa, tornando-a espatulada. (D) Reposicionamento da sonda uretral a partir do óstio uretral externo até a vesícula urinária. (E) Secção transversa do pênis (*) $1,5 \mathrm{~cm}$ caudal ao osso peniano com preservação dos vasos (seta). (F) Espatulação em $1 \mathrm{~cm}$ da borda uretral peniana. (G) Ponto isolado simples em 12 horas (seta). (H) Anastomose término-terminal (seta) entre a uretra peniana $(*)$ e a uretra prostática. (I) Celiorrafia por meio de sutura contínua simples evidenciando a entrada da uretra peniana na cavidade abdominal (seta).

A celiorrafia ocorreu como de rotina, com sutura contínua simples utilizando náilon monofilamentar 2-0, entretanto o primeiro ponto teve início entre 1 e $2 \mathrm{~cm}$ distanciado cranial à anastomose (Fig. 1I). A sutura do subcutâneo foi realizada com fio de náilon monofilamentar 3-0, padrão contínuo ziguezague, e a pele com fio de náilon monofilamentar 4-0, padrão intradérmico. O tempo cirúrgico foi cronometrado desde a incisão abdominal até a execução do último ponto de pele.
Ao final da transposição, cada cão foi levado ao setor de imagem com a sonda posicionada para proceder-se à URCP, administrando-se entre $1 \mathrm{e}$ $2 \mathrm{~mL} / \mathrm{kg}$ de sulfato de bário suspensão mediante a sonda na vesícula urinária (Fig. 2A), pressionando lentamente o embolo e removendoa lentamente para preencher a luz uretral.

Foram realizadas duas projeções radiográficas contrastadas, uma lateral e outra ventrodorsal, e os parâmetros avaliados por meio da URCP foram o derrame na anastomose e o diâmetro luminal em três pontos: meio centímetro distal à anastomose, na anastomose, e meio centímetro 
proximal à anastomose (Fig. 2B). Somente a posição radiográfica lateral foi utilizada para proceder-se as mensurações por meio do programa RadiAnt DICOM viewer 3.4.3®, fazendo-se a conversão de pixel para $\mathrm{cm}$ por meio do programa DICOM converter setup ${ }^{\circledR}$. Foi adotada como medida padrão, para fim comparativo, o diâmetro uretral distal, ou seja, a mais próxima da glande para comparar com o diâmetro da anastomose.

O selamento da sutura foi avaliado por meio do contraste extravasado a partir da anastomose, mensurando-se o volume derramado adjacente e classificando-o segundo Caldas et al. (2004), em ausente, discreto, moderado e severo, contudo fez-se padronização em milímetros conforme a seguir: ausente (-) (Fig. 2C), discreto (até 10 milímetros, +) (Fig. 2D), moderado (entre $10 \mathrm{e}$ 20 milímetros, ++) (Fig. 2E) e severo (acima de 20 milímetros, +++) (Fig. 2F). Ao final dessa etapa, os cadáveres foram encaminhados ao setor de patologia animal do Laboratório Regional de Diagnóstico da UFPel, para destino conforme regulamentação do setor.
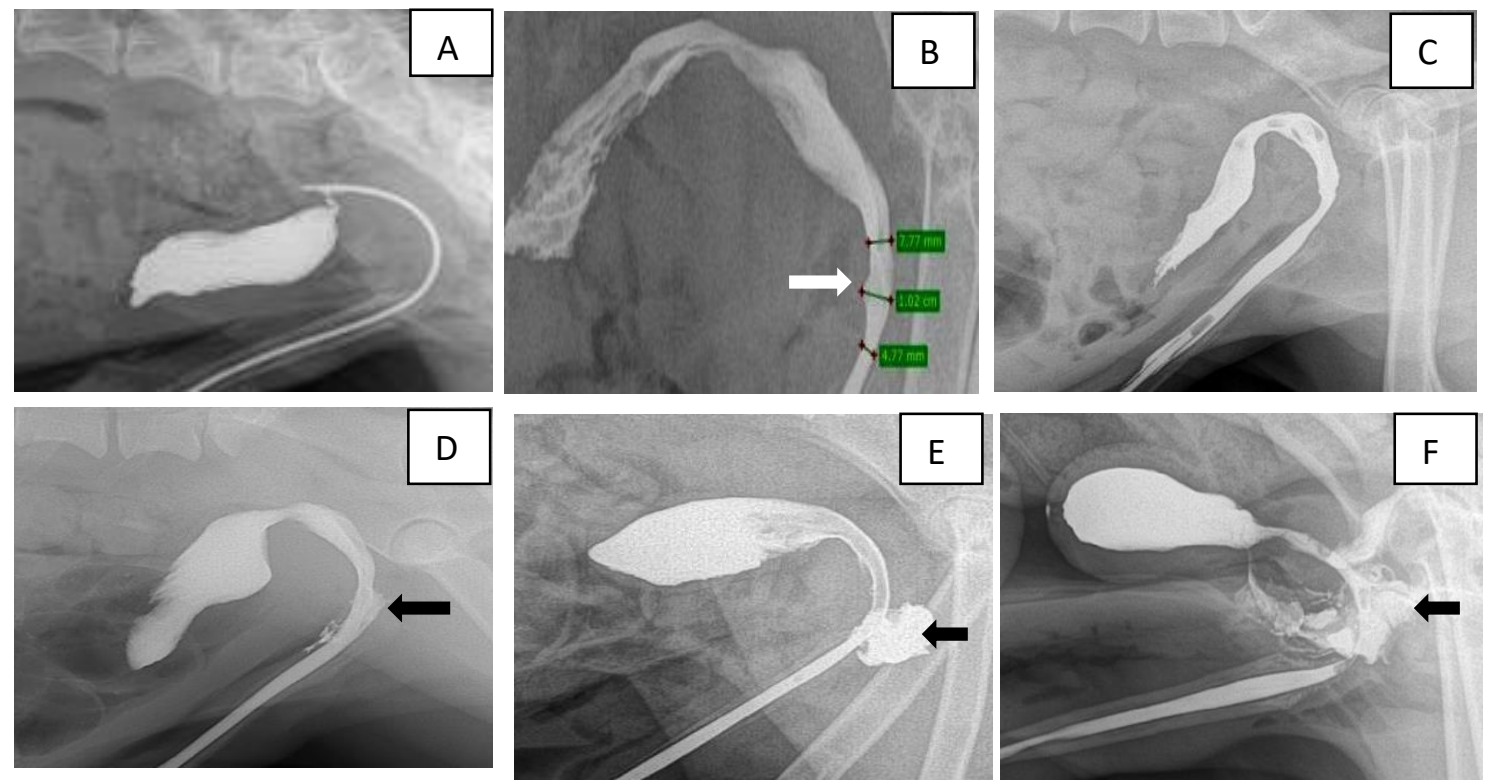

Figura 2. Imagens de uretrografia retrógrada com contraste positivo em cães submetidos \{a técnica de transposição uretral pré-púbica. (A) Inoculação do contraste intrav ssical, via sonda uretral. (B) Pontos de mensuração do diâmetro uretral, onde (*) é o ponto proximal, (') o ponto distal, e a seta a anastomose. (C) Derrame ausente. (D) Derrame discreto (seta). (E) Derrame moderado (seta). (F) Derrame severo (seta).

\section{RESULTADOS}

A execução da técnica mostrou-se simples, em comparação a técnicas de média complexidade. Nos 18 cães, foi possível proceder-se à TUPP sem complicações, mostrando-se ser versátil e eficaz para constituir o desvio do trajeto urinário.

A celiotomia retroumbilical sobre a linha média, com abordagem cutânea paraprepucial, permitiu excelente visibilização anatômica topográfica em todos os animais, contribuindo para o acesso à próstata e à porção cranial da uretra membranosa, sem requerer osteotomia ou sinfisiotomia púbica.
O desvio uretral conferido pela TUPP manteve o fluxo vesical com preenchimento pelo contraste em todos os cães, conforme verificado nas URCP.

A espatulação realizada em ambas as extremidades, após secção da uretra, permitiu ampliar o diâmetro na anastomose em 11 dos 18 animais, conforme verificado nas URCP. Os cães 1 e 7 apresentaram diâmetro menor, quando comparados ao diâmetro padrão; já os cães 2, 5, 8, 14 e 17 obtiveram diâmetros iguais na anastomose. 
O tempo cirúrgico para a TUPP variou entre 130min para o primeiro cão e 40min para o último, com média de $75 \mathrm{~min}$ para a execução da técnica.

O comprimento uretral desde a porção caudal da próstata até o óstio uretral externo teve redução média de $49,97 \%$ (entre $44,7 \%$ para o cão 14 e $55,3 \%$ para o cão 6 ), observando-se que nove dos
18 animais apresentaram perdas acima de $50 \%$ do comprimento uretral, que compreendia segmento da uretra bulbar e membranosa.

A conformação anatômica externa em todos os cães ficou semelhante à de um cão macho orquiectomizado (Fig. 3A), não sendo possível identificar visualmente o desvio do trajeto urinário (Fig. 3B).
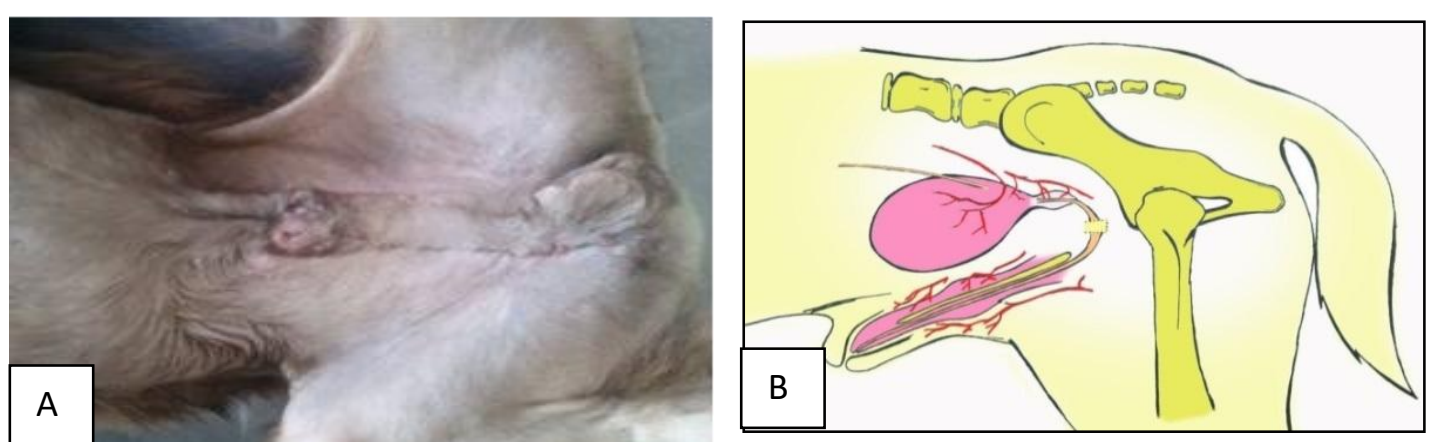

Figura 3. Transposição uretral pré-púbica (TUPP) mediante secção peniana em cadáveres de cães machos. (A) Aspecto anatômico da genitália externa do cão 7. (B) Desenho anatômico esquemático do cão macho com desvio uretral através da TUPP. Autor da imagem B: Charles Lima.

A anastomose mediante sutura simples interrompida foi eficaz para a coaptação das extremidades e, em todos os cães, impediu o extravasamento de contraste enquanto permaneceram com sondas. $O$ selamento na anastomose após a remoção da sonda ocorreu em oito dos 18 animais. Dentre os 10 cães que apresentaram extravasamento de contraste na anastomose, oito compreenderam derrame discreto, o cão 5 apresentou derrame moderado e o cão 18 apresentou derrame acentuado. As imagens da URCP de todos os cães estão ilustradas na Fig. 4 e os parâmetros analisados encontram-se distribuídos na Tab. 2.

\section{DISCUSSÃO}

A reconstrução urogenital tem como objetivo principal restabelecer o adequado esvaziamento vesical. Entre as várias complicações do trato urinário com possibilidade de reconstrução cirúrgica, destaca-se a estenose de uretra com grande prevalência e diversidade de apresentação (Ximenes e Souza Neto, 2010).
Alguns autores consideram desafiador o reparo uretral de defeitos extensos devido à possibilidade de estenoses e derrame urinário (Boothe, 2000; Nuininga et al., 2005; Barbagli et al., 2006; Deliberal et al., 2011), entretanto a TUPP mostrou-se simples, rápida e eficiente em conferir o desvio uretral com manutenção do fluxo urinário.

A estenose pode acometer qualquer segmento uretral deste a próstata até o óstio externo, e a TUPP pode ser alternativa de tratamento para manter o fluxo urinário nos casos de lesões que compreendem a uretra prostática até o segmento caudal ao osso peniano, conforme verificado nas mensurações do comprimento uretral inicial e final à execução da técnica.

A abordagem da uretra pélvica muitas vezes requer osteotomia do púbis (Bjorling, 2003; Katayama et al., 2012), no entanto a transposição uretral aqui proposta não requer osteotomia, uma vez que é executada cranialmente ao púbis, permitindo visibilização ampla do campo cirúrgico. 

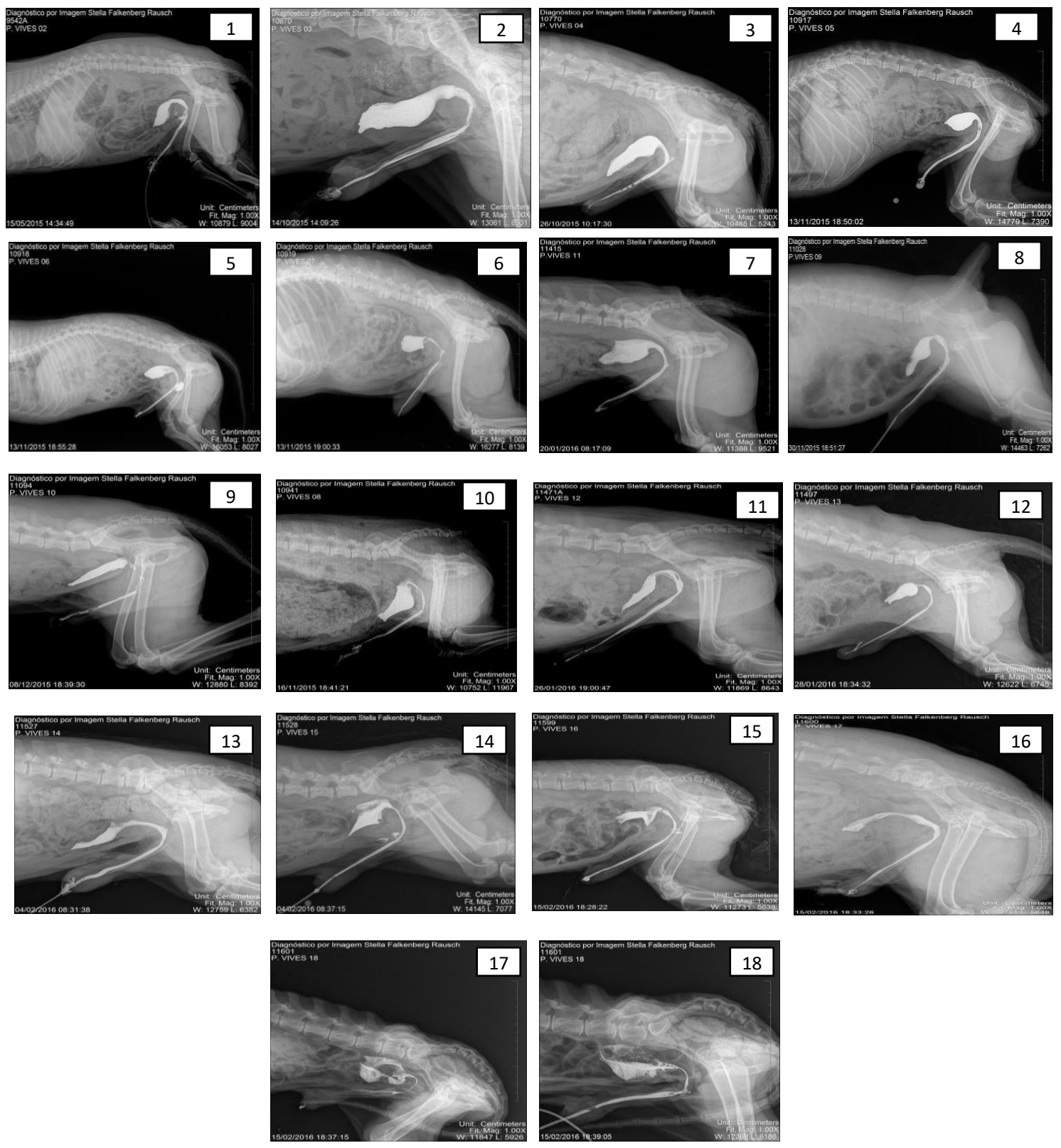

Figura 4. Imagens da uretrocistografia retrógrada com contraste positivo em 18 cadáveres de cães machos submetidos à transposição uretral pré-púbica (TUPP) mediante secção peniana, evidenciando o desvio uretral e a manutenção do fluxo de contraste com preenchimento vesical em todos os animais.

Poucas técnicas reconstrutivas da uretra do cão são mencionadas e incluem enxertos autólogos de mucosa oral (Paulo et al., 2004), fáscia lata (Atalan et al., 2005), carótida conservada (Paulo et al., 2000) e stents vasculares (Flesher et al., 2016), entretanto, embora sejam de fácil execução, segundo os autores, as complicações, a exigência de dois tempos cirúrgicos, o custo elevado e a disponibilidade dos implantes, muitas vezes, inviabilizam o uso destes; em contrapartida, a TUPP é realizada em apenas um tempo cirúrgico, não requer implantes e doadores e disponibiliza tecido uretral suficiente para permitir anastomose sem tensão na sutura. 
Vives et al.

Tabela 2. Parâmetros analisados e resultados obtidos a partir das uretrocistografia retrógrada com contraste positivo de cães submetidos à transposição uretral pré-púbica

\begin{tabular}{|c|c|c|c|c|c|c|c|c|}
\hline Variáveis & $\begin{array}{l}\text { CU I } \\
(\mathrm{cm})\end{array}$ & $\begin{array}{l}\text { CUF } \\
(\mathrm{cm})\end{array}$ & $\begin{array}{c}\text { Perda } \\
\text { uretral } \\
(\%)\end{array}$ & $\begin{array}{c}\text { Diâmetro } \\
\text { na } \\
\text { anastomose }\end{array}$ & $\begin{array}{l}\text { Mensuração } \\
\text { padrão } \\
(\mathrm{cm})\end{array}$ & $\begin{array}{c}\text { Mensuração } \\
\text { na anastomose } \\
(\mathrm{cm})\end{array}$ & $\begin{array}{l}\text { Tempo } \\
\text { cirúrgico } \\
(\min )\end{array}$ & $\begin{array}{c}\text { Derrame } \\
\text { sem } \\
\text { sonda }\end{array}$ \\
\hline cão 1 & 19,3 & 9,0 & $53,4 \%$ & menor & 0,56 & 0,48 & 130 & + \\
\hline cão 2 & 23,5 & 12,2 & $48,1 \%$ & igual & 0,44 & 0,44 & 122 & - \\
\hline cão 3 & 19,5 & 10,1 & $48,2 \%$ & maior & 0,55 & 0,77 & 105 & + \\
\hline cão 4 & 18,5 & 8,9 & $51,9 \%$ & maior & 0,55 & 0,67 & 100 & - \\
\hline cão 5 & 24,8 & 11,8 & $52,2 \%$ & igual & 0,49 & 0,49 & 107 & ++ \\
\hline cão 6 & 19,0 & 8,5 & $55,3 \%$ & maior & 0,44 & 0,68 & 95 & + \\
\hline cão 7 & 20,5 & 10,3 & $49,8 \%$ & menor & 0,58 & 0,43 & 90 & + \\
\hline cão 8 & 20,5 & 10,9 & $46,8 \%$ & igual & 0,53 & 0,53 & 80 & + \\
\hline cão 9 & 21,9 & 10,3 & $53,0 \%$ & maior & 0,57 & 0,58 & 75 & + \\
\hline cão 10 & 19,2 & 10,1 & $48,0 \%$ & maior & 0,61 & 0,73 & 72 & - \\
\hline cão 11 & 22,0 & 10,0 & $54,5 \%$ & maior & 0,45 & 0,79 & 63 & - \\
\hline cão 12 & 18,5 & 10,0 & $46,0 \%$ & igual & 0,42 & 0,42 & 50 & - \\
\hline cão 13 & 27,5 & 15,0 & $45,5 \%$ & maior & 0,8 & 1,5 & 52 & - \\
\hline cão 14 & 19,0 & 10,5 & $44,7 \%$ & maior & 0,34 & 0,35 & 48 & + \\
\hline cão 15 & 18,2 & 9,5 & $51,0 \%$ & maior & 0,24 & 0,33 & 47 & + \\
\hline cão 16 & 19,8 & 9,7 & $51,0 \%$ & maior & 0,47 & 1,02 & 45 & - \\
\hline cão 17 & 18,0 & 8,6 & $52,3 \%$ & igual & 0,34 & 0,34 & 43 & - \\
\hline cão 18 & 23,8 & 12,4 & $47,9 \%$ & maior & 0,34 & 0,39 & 40 & +++ \\
\hline
\end{tabular}

Fonte: Arquivo pessoal, CUI - comprimento uretral inicial, CUF - comprimento uretral final.

Recentemente, duas técnicas semelhantes à TUPP foram relatadas para cães, propondo-se a secção peniana em região escrotal com desvio uretral cranialmente ao púbis para anastomose extra pélvica, dando continuidade ao fluxo urinário.

Minier et al. (2016) ressecaram um segmento caudal da uretra membranosa comprometida por neoplasia, entretanto a execução requereu dois tempos cirúrgicos. $\mathrm{O}$ primeiro com decúbito ventral e abordagem perineal para exérese da massa associada à uretra, desviando a porção uretral cranial hígida em direção à cavidade abdominal. Na sequência em decúbito dorsal, recuperaram o coto através de um anel inguinal, fazendo a anastomose término-terminal por meio de sutura simples interrompida na uretra esponjosa dissecada do corpo cavernoso, e embora o canal inguinal pareça estreito para a passagem da uretra membranosa, os autores referiram ausência de tensão na anastomose, manutenção do fluxo e continência urinária.

Contrária à técnica descrita acima, a TUPP requer celiotomia, contudo possibilita inspeção da bexiga, próstata e segmento cranial da uretra membranosa, permitindo dissecção cuidadosa da vascularização e inervação local, facilitando, assim, a secção uretral. Além disso, a TUPP requer apenas um tempo cirúrgico, e não preconiza a dissecção do corpo uretral esponjoso, separando-o dos corpos cavernosos, uma vez que a manipulação nesse tecido pode desencadear a estenose (Ximenes e Souza Neto, 2010).

Bacon et al. (2016) também executaram o desvio da uretra esponjosa cranial ao púbis mediante secção peniana em dois cães acometidos por neoplasias e submetidos à prostatectomia e à cistectomia total, requerendo anastomose uretero-ureteral. Os autores verificaram benefícios da técnica semelhantes à TUPP, por não requerer osteotomia do púbis, ausência de tensão na anastomose e manutenção do fluxo urinário, e destacaram esse procedimento como de salvamento, devido à ocorrência de incontinência urinária permanente e pielonefrite bacteriana pelo acentuado encurtamento do trajeto urinário.

Considerando-se as estruturas anatômicas, a abordagem para a execução da TUPP é exclusivamente abdominal e a viabilidade da técnica consiste em deslocar a próstata cranialmente, uma vez que esta já apresenta um 
posicionamento dinâmico, quando a vesícula urinária repleta traciona a próstata para a cavidade abdominal.

Os vasos e nervos uretrais preservados durante o procedimento no cadáver objetivaram mimetizar a execução da técnica in vivo e, assim, manter a viabilidade vascular, a cicatrização e a continência urinária.

Ainda referente às considerações anatômicas, a diferença do diâmetro uretral entre as bordas coaptadas é minimizada pela espatulação maior na uretra peniana, visto que esta possui um diâmetro menor nesse segmento. Já no segmento membranoso, a incisão longitudinal é menor, obtendo-se uma anastomose justaposta.

As técnicas para restituir o fluxo urinário de cães, nas ressecções extensas da uretra membranosa, são escassas, o que frequentemente leva os cirurgiões a optarem pela uretrostomia pré-púbica associada ou não à ablação da genitália externa (Smeak, 2000; Katayama, 2012), enquanto na TUPP, a manutenção do pênis e prepúcio conferiu conformação anatômica idêntica a um cão castrado, elimina complicações, como dermatite amoniacal, reduz a ocorrência de cistite e o impacto estético ao tutor do animal (Vives et al., 2017).

Diversos autores citaram a estenose como uma das complicações de maior ocorrência pósanastomose uretral (Raney et al., 1977; Ghozzi et al., 2010; Ximenes e Souza Neto, 2010; Deliberal et al., 2011; Regueiro et al., 2012). Objetivando-se evitar essa complicação, a espatulação das extremidades uretrais foi realizada conforme descrito por Silva et al. (2002), ampliando-se o diâmetro na anastomose, como observado nas URCP de 13 dos 18 cães.

Em apenas dois cães houve diminuição do lúmen, provavelmente pela flexão peniana para aproximar a uretra prostática, formando um ângulo agudo e, consequentemente, diminuição na luz uretral verificada na URCP, contudo a espatulação, em ambas as bordas, foi competente em permitir o fluxo do contraste até a vesícula urinária. Como alternativa para essa complicação, verificou-se, durante a execução da técnica, que, ao manter-se o segmento peniano mais curto e fazer-se a espatulação na face peniana ventral, os corpos cavernosos deram sustentação ao corpo esponjoso, o que tornou a flexão uretral mais suave e minimizou a constrição na anastomose.

URCP é o exame de eleição para avaliar-se solução de continuidade e alterações luminais da uretra (Kealy e Mcallister, 2010); assim, foi possível avaliar a manutenção do fluxo urinário e o preenchimento vesical pelo contraste em todos os cães, mesmo com o desvio do trajeto uretral ocasionado pela TUPP, inclusive nos dois animais que apresentaram imagem de constrição na anastomose.

O extravasamento de contraste verificado nas URCP em 10 dos 18 cadáveres ocorreu somente após a remoção da sonda uretral e está relacionado à falha do selamento na anastomose por meio da sutura interrompida simples. Dentre estes, em apenas um o derrame foi classificado como moderado e em outro como acentuado, os outros sete apresentaram extravasamento discreto, que, na técnica in vivo, provavelmente não traria prejuízo aos pacientes (Caldas et al., 2004), uma vez que estes permaneceriam a com sonda no pós-operatório, promovendo desvio urinário até que ocorresse cicatrização da anastomose.

A colocação de suturas adicionais ou de mais planos de sutura para obter-se o selamento completo na anastomose não está indicada, uma vez que o excesso de implantes estimula a formação de fibrose (Barbagli et al., 2006; Souza et al., 2014), e deve-se considerar ainda que o tecido in vivo tem o processo cicatricial iniciado logo após a anastomose, impermeabilizando a sutura entre três e cinco dias, período em que a urina seria desviada através da sonda (Boothe, 2000; Bjorling, 2003).

A celiorrafia executada deixando-se o ponto inicial distanciado entre 1 e $2 \mathrm{~cm}$ cranialmente à anastomose (penetração da uretra na cavidade abdominal) objetivou simular a técnica in vivo (Vives et al., 2017) recomendada para evitar que o processo cicatricial da parede possa fazer constrição no ponto em que a uretra adentra a cavidade abdominal.

A experimentação da TUPP em cadáveres de cães advindos de hospitais veterinários segue as recomendações de Matera (2008) e Scherer (2009), as quais, além de protegerem os direitos 
dos animais na pesquisa científica, mostraram-se eficientes para comprovar a viabilidade anatômica e a exequibilidade da técnica, principalmente por tratar-se de um procedimento inovador que requereu também o treinamento cirúrgico na própria espécie (Mccarthy et al., 2002). Embora não fosse possível avaliar o processo cicatricial em cadáveres, a técnica foi executada preconizando-se preservar estruturas como vascularização e inervação local, objetivando a aplicação prática na rotina.

Em estudo prospectivo, Saito (2010) verificou que, após a $20^{\mathrm{a}}$ prostatectomia retropúbica em humanos, houve redução nas complicações e diminuição em $70 \%$ no tempo cirúrgico. Neste estudo, considerando-se 18 cães para execução da TUPP, somente a partir do $12^{\circ}$ cão se obteve redução em $50 \%$ do tempo cirúrgico.

A reconstrução da uretra é um processo em constante evolução, e novas tecnologias devem ser discutidas para que o paciente receba padrão terapêutico mais adequado. Esse objetivo será possível com aperfeiçoamento técnico, desenvolvimento de novas pesquisas e tradução dos resultados científicos para a prática clínica diária (Barbagli et al., 2012).

\section{CONCLUSÃO}

A transposição uretral pré-púbica apresenta-se como uma técnica cirúrgica viável sob o aspecto anatômico, conferindo conformação estética da genitália externa idêntica à de um cão macho orquiectomizado, exime a tensão na anastomose e permite esvaziamento vesical, uma vez que há manutenção adequada do lúmen uretral.

\section{REFERÊNCIAS}

ATALAN, G.; CIHAN, M.; SOZMEN, M.; OZAYDIN, I. Repair of urethral defects using fascia lata autografts in dogs. Vet. Surg., v.34, p.514-518, 2005.

BACON, N.; SOUZA, C.H.; FRANZ, S. Total cysto-prostatectomy: technique description and results in 2 dogs. Can. Vet. J., v.57, p.141-146, 2016.

BARBAGLI, G.; GUAZZONI, G.; PALMINTERI, E.; LAZZERI, M. Anastomotic fibrous ring as cause of stricture recurrence after bulbar onlay graft urethroplasty. J. Urol., v.176, p.614-619, 2006.

BARBAGLI, G.; SANSALONE, S.; DJINOVIC, R. et al. Current controversies in reconstructive surgery of the anterior urethra: a clinical overview. Int. Braz. J. Urol., v.38, p.307-311, 2012.

BJORLING, D.E. The urethra. In: SLATTER, D. Textbook of small animal surgery. 3.ed. Philadelphia: Saunders, 2003. v.2, p.1638-1649.

BOOTHE, H.W. Managing traumatic urethral injuries. Clin. Tech. Small. Anim. Pract., v.15, p.35-39, 2000

BRINKER, W.O; PIERMATTEI, D.L.; FLO, G.L.F. Fraturas da pelve, ortopedia e tratamento de fraturas de pequenos animais. 4.ed. [Barueri, SP.]: Manole, 2009. cap.15, p.491-521.

CALDAS, F.P.; BENEDETT, A.; GOLDSCHIMIT, H. Controvérsias e complicações em anastomoses vesicouretrais por videocirugia. 2004. Disponível em <http://www.urovideo.org/pictures/artigos/forca download.php?file $=14032011182402130013784$ 2.pdf>. Acessado em 20 jul. 2014

DELIBERAL, A.L.; SILVA FILHO, E.F.; COSTA A.P. et al. Ruptura de uretra prostática em cão - relato de caso. In: CONGRESSO DE INICIAÇÃO CIENTÍFICA DA UNIVERSIDADE DE RIO VERDE, 5., 2011, Rio Verde. Anais... Rio Verde, GO: FESURV, 2011. p.193-195.

FLESHER, K.; WEISSE, C.; BERENT, A.; LIN, R. Urinary bladder retroversion and neourethrocystostomy for treatment of inadvertent prostatectomy and urethrectomy in a dog. J. Am. Vet. Med. Assoc., v.248, p.538-543, 2016.

GHOZZI, S.; GHORBEL, J.; DRIDI, M. et al. Stenose de l'anastomose vesico-urethrale apress prostatectomie radicale (a propos de 7 cas). $J$. Maroc. Urol., v.19, p.23-29, 2010.

KATAYAMA, M.; OKAMURA, Y.; KAMISHINA, H. et al. Urinary diversion via preputial urethrostomy with bilateral pubicischial osteotomy in a dog. Turk. J. Vet. Anim. Sci. Tübitak, v.36, p.730-733, 2012.

KEALY, J.K.; MCALLISTER, H. Diagnostic radiology and ultrasonography of the dog and cat. 4.ed. Philadelphia: Hardcover, 2010. p.441. 
KEMPER, B.; FIGUEIREDO, L.M.; SEVERO, M.S.; TUDURY, E.A. Consequências do trauma pélvico em cães. Cienc. Anim. Bras., v.12, p.311321, 2011.

MATERA, J.M. O ensino de cirurgia: da teoria à prática. CONGRESSO BRASILEIRO DE BIOÉTICA E BEM-ESTAR ANIMAL / SEMINÁRIO NACIONAL DE BIOSSEGURANÇA E BIOTECNOLOGIA ANIMAL, 1., Recife, 2008. Anais... Recife: CFMV, 2008. p.96-99.

MCCARTHY, M.C.; RANZINGER, M.R.; NOLAN, D.J. et al. Accuracy of cricothyroidotomy performed in canine and human cadaver models during surgical skills training. J. Am. Coll. Surg., v.195, p.627-629, 2002 .

MINIER, K.; BEMELMANS, I.; BENOIT J. An end-to-end urethral anastomosis after inguinal tunnelization: a new technique in a dog. J. Small Anim. Pract., v.57, p.100-104, 2016.

NUININGA, J.E.; DE GIER, R.P.; VERSCHUREN, R.; FEITZ, W.F. Long-term outcome of different types of 1-stage hypospadias repair. J. Urol., v.174, p.1544-1548, 2005.

PAULO, N.M.; FISCHER, P.; MATOS, M.P.C. et al. Uretroplastia experimental de substituição em cães com segmentos homólogos de artéria carótida conservada em glicerina. Cienc. Anim. Bras., v.1, p.65-71, 2000.

PAULO, N.M.; SILVA, F.F.; BRITO, G.A. et al. Reconstrução uretral com retalho autógeno de mucosa bucal após uretrostomia, em cães. Acta. Circ. Bras., v.19, p.110-114, 2004.

RANEY, A.M.; SCOTT, M.P.; BROWNSTEIN, P.K.; BOGAEV, J.H. Urethral injury experimental study. Urology, v.9, p.281-283, 1977.
REGUEIRO J.C.; CARRASCO, J.C.; ALVAREZ, R. et al. Opciones de tratamiento quirúrgico en la estenosis de uretra bulbar. Acta Urol., v.37, p.167-173, 2012.

SAITO, F.J.A. Curva de aprendizado inicial da prostatectomia radical retropúbica. 2010. 67f. Tese (Doutorado em Ciência) - Faculdade de Medicina da Universidade de São Paulo, São Paulo, SP.

SCHERER, S. Desenvolvimento de modelo experimental em cadáver de cão conservado com a solução de Larssen modificada para treinamento em videocirurgia: nefrectomia total $e$ tireoidectomia. 2009. 78f. Dissertação (Mestrado em Morfologia, Cirurgia e Patologia Animal) - Faculdade de Veterinária da Faculdade do Rio Grande do Sul, Porto Alegre, RS.

SILVA, F.F.; PAULO, N.M.; BRITO, G.A. et al. Avaliação da triangulação da anastomose término-terminal de fragmento de mucosa bucal na reconstrução uretral: estudo experimental no cão. Acta Circ. Bras., v.17, p.327-331, 2002.

SMEAK, D.D. Urethrotomy and urethrostomy in the dog. Clin. Techn. Small Anim. Pract., v.15, p.25-34, 2000 .

SOUZA, L.A.; FREITAS, P.M.C.; BERETTA, D.C. et al. Estudo comparativo das suturas swift extramucosas versus pontos simples contínuos contaminantes e cusching, na rafia intestinal em coelhos da raça Nova Zelândia. Vet. Notícias, v.12, p.82, 2014.

Vives, P., Braga, F.A., Rappeti, J. et al. Transposição e anastomose uretral pré-púbica em um cão macho com estenose extensa da uretra intrapélvica. Arquivo Brasileiro de Medicina Veterinária e Zootecnia, v.69, p.1331-1334, 2017.

XIMENES, S.F; SOUZA NETO, J.L. Reconstrução uretral. In: NARDOZZA JÚNIOR, A.; ZERATI FILHO, M.; REIS, R.B. Urologia fundamental. São Paulo: Planmark, 2010. v.36, p.320-326. 